\title{
ESTADOS UNIDOS EN APEC: DEL PROYECTO AL SABOTAJE DE LA COMUNIDAD DE ASIA PACÍFICO
}

\author{
JUAN JOSÉ RAMÍREZ BONILLA \\ ORCID: https://orcid.org/0000-0001-6109-2269 \\ El Colegio de México, A. C.
}

En 2019, el foro Asia-Pacific Economic Cooperation (APEC) cumplió 30 años, promoviendo la cooperación intergubernamental, más allá del campo económico, privilegiado cuando el foro fue creado. El proyecto original buscaba crear un espacio de diálogo, basado en una estructura institucional laxa, en la consulta y el consenso, así como en decisiones no vinculantes, sobre temas de cooperación económica entre los gobiernos de Australia y Nueva Zelanda con los de Japón, Corea, Brunéi, Filipinas, Indonesia, Malasia, Singapur y Tailandia. La administración republicana de George Bush presionó para imponer la inclusión de los Estados Unidos y de Canadá (con cuyo gobierno recién había puesto en práctica un acuerdo comercial bilateral), desde la primera reunión oficial, en 1989.

En 1990, el gobierno singapurense, propuso invitar a los gobiernos de la República Popular China (RPCh) y de la República de China (RCh o Taiwán), así como a las autoridades administrativas de Hong Kong (APEC, 1990); Lee Kwan Yew fue de los primeros en comprender el alcance de la política de "contención sin aislamiento" de China, propuesta por Richard M. Nixon (1967) y operó para que APEC deviniese un mecanismo de contención, tanto de China, como de los Estados Unidos, convirtiéndolos en contrapesos recíprocos dentro del foro; así, en 1991, las tres entidades políticas chinas debutaron como miembros de

D.R. () 2020. Anuario Asia Pacífico

Licencia Creative Commons Atribución-NoComercial-SinDerivar (CC BY-NC-ND) 4.0 Internacional 
APEC. Con esto, el foro entró en una dinámica en la cual los invitados impusieron el ritmo de baile a los organizadores de la fiesta.

El gobierno de la RPCh impuso cambios en la jerga del foro: dada su relación con el gobierno de Taiwán, obligó al uso de la denominación Chinese Taipei, para referirse a la República de China como miembro del foro; también presionó para utilizar el sustantivo "economía", en vez de "gobierno", para referirse a los miembros oficiales del foro (APEC, 1991).

En 1993, la administración Clinton cambió el ritmo del desarrollo del foro: convocó la primera reunión de jefes de Estado y de gobierno, para reemplazar la Reunión Ministerial como máxima instancia del foro y para tornar vinculantes sus decisiones. La reacción del gobierno chino no tardó: censuró el término "reunión de jefes de Estado y de gobierno" y la administración Clinton recurrió al eufemismo "Reunión de Líderes Económicos de APEC" para convocar a los jefes de Estado y de gobierno integrantes del foro.

En los años siguientes, diversos factores funcionaron como sordina para la oposición sino-estadounidense; entre ellos destacaron la política de "contención sin aislamiento" de China (propuesta por Richard M. Nixon desde 1967 y practicada por el gobierno estadounidense a partir del establecimiento de relaciones diplomáticas bilaterales); durante la década de 1990, la concentración del gobierno chino en las reformas económicas domésticas; y acontecimientos regionales (la crisis mexicana de 1994, la crisis asiática de 1997 y la recesión estadounidense de 2001) o globales (el "combate contra el terrorismo internacional" de la administración George W. Bush, durante 2001-2008).

Pero, en 2011, ante la creciente influencia económica y política de la RPCh en la región del Pacífico, la administración Obama se propuso realizar el "giro hacia el Pacífico", abandonando la política de "contención sin aislamiento" de China y redefiniendo las alianzas con los principales socios asiáticos del Pacífico; el objetivo era aislar política y económicamente a China; los instrumentos privilegiados por la administración Clinton fueron el Trans Pacific Partnership Agreement (TTP) y la renegociación de los vínculos estratégicos con los aliados históricos de la región asiática del Pacífico. La llegada de Donald Trump a la presidencia de los Estados Unidos acentuó ese giro en la política exterior estadounidense, pasando a la confrontación directa con el gobierno chino (para liquidar 
definitivamente la política de "contención sin aislamiento" de China) y al uso de mecanismos coercitivos para imponer los intereses estadounidenses a sus aliados y a su contrincante del Pacífico.

En este contexto general, nuestro trabajo tiene como objetivo principal analizar los cambios en la política estadounidense en relación con APEC. Como argumento central de nuestro trabajo consideramos que, en el contexto de la región del Pacífico, la política de “contención sin aislamiento" de China, con el tiempo, devino un mecanismo de contención recíproca entre los Estados Unidos y China, de tal manera que la política exterior de cada gobierno es modulada por la de su contraparte, acentuando la interdependencia resultante de la globalización. En este marco, la primera parte de nuestro texto está dedicada a recuperar el espíritu original de la política de "contención sin aislamiento" de China, a partir de los argumentos del artífice del Watergate. En la segunda parte, resaltamos el vaivén entre la propuesta de una "comunidad del Pacífico", impulsada por William Clinton sobre la base del “regionalismo abierto", propuesto por el APEC Eminent Persons Group (APEC, 1993), y el proyecto para aislar a China, formulado por la secretaria de Estado Hillary Clinton (2011), durante la primera administración Obama. Finalmente, la tercera parte de nuestro texto tiene como objetivo analizar las repercusiones del regionalismo propio de la administración Trump sobre las iniciativas multilaterales de integración económica (el Área de Libre Comercio de América del Norte - ALCAN—, el Trans-Pacific Partnership — TPP— y el Área de Libre Comercio de Asia-Pacífico - ALCAP_-), sobre las funciones de la Organización Mundial de Comercio (OMC) y sobre las relaciones con el gobierno de la RPCh.

\section{RICHARD M. NIXON Y LA “CONTENCIÓN SIN AISLAMIENTO” DE CHINA}

Antes de llegar a la presidencia de los Estados Unidos, previo al final de la intervención militar en Vietnam y prior al establecimiento de relaciones diplomáticas con el gobierno de la RPCh, Richard M. Nixon, en “Asia after Viet Nam” (1967), definió las líneas de un análisis que han sido repetidas una y otra vez, bajo diferentes modalidades por múltiples autores; Nixon destacaba la necesidad de "construir los nervios de una Comunidad del Pacífico", basada en el progreso económico de las sociedades asiáticas y en las responsabilidades 
compartidas entre asiáticos y estadounidenses para garantizar la seguridad y la estabilidad de la región.

Nixon comenzaba con un juicio novedoso; para él, "la presencia estadounidense [en Asia] ha proporcionado pruebas tangibles y altamente visibles de que el comunismo no es necesariamente [...] el futuro de Asia”. Por el contrario, el presidente en ciernes consideraba que, "alrededor de China, las naciones devienen occidentales, sin dejar de ser asiáticas". Esa occidentalización de los asiáticos, por supuesto, habría sido el resultado de la adopción y adaptación de las instituciones estadounidenses a los diferentes contextos nacionales asiáticos. Ahora bien, esos contextos nacionales permitían entrever una suerte de tensión entre el desarrollo de nuevos nacionalismos (basados en las diversidades sociales, lingüísticas, culturales, etc.) y la construcción de un "regionalismo asiático".

Los nuevos nacionalismos permitirían, según Nixon, superar las viejas concepciones sobre el carácter opresor de los "colonialistas", para ver a los Estados Unidos, más bien, como un "protector"; además, tendrían como fundamento los progresos realizados por Japón, Corea, Hong Kong, Taiwán, Tailandia, Singapur y Malasia; pues

[...] sus métodos de gestión económica tienen ciertos rasgos en común: una confianza primordial en la empresa privada y en los mecanismos de fijación de precios del mercado como determinante de las decisiones comerciales; un ritmo de expansión monetaria para igualar el crecimiento de la producción; receptividad a la inversión de capital privado, tanto nacional como extranjero, incluyendo incentivos como ventajas fiscales y la rápida aprobación gubernamental de los proyectos propuestos; programas nacionales imaginativos para tratar problemas sociales; $y$, no menos importante, una actitud generalmente restringida en la planificación gubernamental, con el papel del gobierno más sugerente que coercitivo. En resumen, estas naciones han descubierto y aplicado las lecciones de América [...] (Nixon, 1967). ${ }^{1}$

Pese al ombliguismo, Nixon se vio forzado a reconocer que el gobierno japonés "se mueve gradual y cautelosamente hacia una función más amplia como líder” regional y que las disposiciones constitucionales, impuestas durante la ocupación militar estadounidense,

\footnotetext{
${ }^{1}$ Son libres todas las traducciones del inglés al español.
} 
impedían al gobierno de Japón desempeñarse plenamente como tal líder: "es simplemente no realista esperar que una nación se mueva hacia el primer rango de los mayores poderes y que, para su propia seguridad, sea totalmente dependiente de otra nación, por más estrechos que sean sus vínculos".

La función de Japón como líder regional permite volver al tema del "regionalismo asiático", cuya coherencia, según Nixon, "se refleja en la disposición a considerar los problemas y las lealtades en términos regionales, y a desarrollar enfoques regionales para las necesidades de desarrollo y para la evolución de un nuevo orden mundial". Nixon pone de realce esta peculiaridad de Asia del Pacífico, pero omite establecer el vínculo directo entre esa disposición regionalista y la influencia japonesa antes (mediante el proyecto de la Esfera de Co-Prosperidad de la Gran Asia Oriental) y después (a través de la reconstrucción de los nexos económicos con los vecinos del Pacífico asiático) de la guerra del Pacífico. En todo caso, la cooperación intergubernamental y la concomitante integración regional estuvieron presentes a lo largo de prácticamente todo el siglo XX; así lo mostraba, desde la década de 1930, Akamatsu Kaname (1961) a través de su sugerente "formación de los gansos silvestres". Nixon y posteriormente los promotores de APEC cosecharon en un suelo previamente trabajado por los promotores del regionalismo nipón.

Ahora bien, habiendo descartado el comunismo como futuro ineluctable de Asia, Nixon consideraba las ambiciones de la China de Mao el mayor riesgo para la región asiática del Pacífico y proponía que las "naciones [...] se muevan rápidamente para establecer un marco asiático indígena para [garantizar] su propia seguridad futura". En ese marco, Nixon propuso su política de “contención sin aislamiento" de China, consistente:

En el corto plazo, [en] una política de firme dominio, sin gratificación, de una contrapresión creativa diseñada para persuadir a Pekín de que sus intereses sólo pueden ser atendidos aceptando las reglas básicas de la civilidad internacional. En el largo plazo, significa atraer China nuevamente a la comunidad mundial, como una gran nación en progreso, no como el epicentro de la revolución mundial.

Como buen adepto de la real politik, Nixon consideraba que esa política "de firme dominio" sobre las ambiciones asiáticas de China "debería ser ejercida por las naciones 
asiáticas", respaldadas por “el poder último de los Estados Unidos”. El artífice del Watergate concluía señalando que "la pauta central del futuro en las relaciones asiático-estadounidenses debe ser el apoyo estadounidense a las iniciativas asiáticas”.

En resumen: para disuadir al gobierno maoísta de abandonar la exportación del comunismo, Nixon estableció como finalidad política última la inclusión de la China comunista en la comunidad internacional; para conseguir ese fin, proponía la inclusión de China en una comunidad de naciones asiáticas pujantes (respaldada por el poder omnímodo estadounidense) y en las instituciones multilaterales del entonces denominado "mundo libre" (impulsadas por el gobierno estadounidense después de la guerra). Posterior a la controvertida visita de Nixon a Mao Tse-tung, en 1972, Henry Kissinger (2011) completaría el esquema, incluyendo un sistema de relaciones bilaterales sino-estadounidenses, garante de la evolución pacífica de China. Con el tiempo, el entramado institucional de la "contención sin aislamiento" de China fue tan efectivo que profundizó la interdependencia de ambos gobiernos y la política exterior para la región del Pacífico de uno acabó determinando la del otro. La evolución de China dirigida por los Estados Unidos se tornó en una coevolución sino-estadounidense.

\section{Clinton vs. Clinton}

Las presiones estadounidenses para transformar APEC en un foro institucionalizado y vinculante comenzaron en 1992, con la instauración de un secretariado permanente, acogido por el gobierno singapurense. En enero de 1993, William Clinton llegó a la presidencia de los Estados Unidos y heredó la responsabilidad de organizar la Reunión Ministerial de APEC de ese año; sin embargo, con la cobertura moral del Grupo de Personas Eminentes de APEC (GPE), la administración Clinton decidió dar una vuelta adicional a la tuerca de la institucionalización del foro y dotarlo de un objetivo: la creación de una Comunidad de Asia Pacífico, basada en los principios del "regionalismo abierto" pregonado por el GPE; sin embargo, durante el lapso que va de la crisis asiática de 1997 al final de la administración Bush, en 2009, el gobierno estadounidense se desentendió de la región del Pacífico y el vacío fue llenado por China, para desarrollar y consolidar su presencia en ella; en ese nuevo contexto, la administración Obama dio los primeros pasos para poner término tanto al 
proyecto de William Clinton sobre la Comunidad de Asia Pacífico como a la política de "contención sin aislamiento" de China, mediante la negociación del TTP y el "giro hacia el Pacífico", propuesto por la secretaria de Estado Hillary Clinton.

\section{William Clinton y la Comunidad de Asia Pacífico}

El eje del proyecto del GPE y, por ende, de la administración Clinton fue el mismo pregonado por Nixon: el proyecto de la comunidad de Asia Pacífico, sustentado, por un lado, en un crecimiento económico derivado del sistema comercial multilateral y, por el otro, en las crecientes interdependencia y apertura económicas, resultantes de $a$ ) la reducción de barreras a la circulación de bienes, capitales y personas; $b$ ) la superación de las distancias y de los tiempos de comunicación; c) la compartición de ideas, conocimientos científicos y técnicos, así como la difusión del mejoramiento de las condiciones de vida (APEC, 1993).

En ese marco, la administración Clinton indicaba: "acogemos con beneplácito el desafió que nos presenta el Informe del Grupo de Personas Eminentes de APEC (GPE) para lograr el libre comercio en Asia Pacífico, para avanzar en la liberalización del comercio mundial y para poner en marcha programas concretos para avanzar hacia esos objetivos en el largo plazo" (APEC, 1993).

El GPE había sido instituido durante la reunión ministerial de 1992, en Bangkok, con la encomienda de "enunciar una visión para el comercio en la región de Asia Pacifico" (APEC, 1993b). Tal visión, señaló más tarde el GPE, debería descansar sobre los principios de comercio e inversiones libres, cooperación internacional, solidaridad regional, beneficio mutuo, respeto mutuo e igualdad, pragmatismo, toma de decisiones sobre la base del consenso e implementación sobre la base de la flexibilidad, regionalismo abierto. Sobre el principio del "regionalismo abierto", los miembros del GPE fueron bastante claros al definirlo como:

[...] un proceso de cooperación regional cuyo resultado no es sólo la reducción real de las barreras internas (intrarregionales) a la interacción económica, sino también la reducción real de las barreras externas a las economías que no forman parte de la empresa regional; sobre todo, nuestro compromiso con el proceso de liberalización global no se ve comprometido de 
ninguna manera; de hecho es enfatizado y fortalecido, porque cualquier empresa regional gobernada por el principio del regionalismo abierto será, por definición, un componente básico y contribuirá a una economía global más libre. Sin ninguna reserva, nos oponemos firmemente a la creación de un bloque comercial interno que se desviaría de la búsqueda del libre comercio mundial ${ }^{2}$ (APEC, 1995).

Más adelante volveremos sobre el tema; por ahora, basta señalar que, en 1993, la administración Clinton adoptó el principio del "regionalismo abierto" y la liberalización comercial en el marco de los organismos multilaterales como los medios para construir la Comunidad de Asia Pacífico; ahora bien, también cabe señalar que el GPE delineó el programa de trabajo seguido durante las reuniones posteriores de los líderes: definir el objetivo de la liberalización comercial, utilizar como medio un programa pragmático de facilitación comercial y una modesta institucionalización de APEC (APEC, 1993b).

Adicionalmente, durante la primera reunión de líderes, la administración Clinton propuso tres iniciativas institucionales ambiciosas: la primera fue la convocatoria de los jefes de Estado y de gobierno para participar en la Reunión de Líderes Económicos de APEC, en Blake Island, en noviembre de 1993. En términos del funcionamiento del foro, la reunión de líderes significó una solución a medias entre la informalidad y la obligatoriedad de las iniciativas de los dirigentes políticos. En efecto, después de la primera reunión, los gobiernos subsiguientes entraron en una dinámica de fuite en avant: sobre la base de los compromisos alcanzados en la primera reunión, cada uno de ellos fue precisando y ampliando las iniciativas para dar concreción a las decisiones originales, pero sin llegar a aceptarlas como obligatorias.

La segunda iniciativa de la administración Clinton fue el llamado para establecer "un Foro de Negocios del Pacífico para identificar temas que APEC debe abordar para facilitar el comercio y las inversiones regionales, así como para alentar un mayor desarrollo de las redes de negocios en la región" (APEC, 1993); esa tarea fue facilitada por la existencia previa del Pacific Basin Economic Council, cuyos integrantes rápidamente se movilizaron para crear el actual APEC Business Advisory Council (ABAC).

${ }^{2}$ Las cursivas son del GPE. 
La tercera iniciativa fue el "Programa de Educación de APEC, para desarrollar la cooperación regional en educación superior, estudiar temas clave de la economía regional, mejorar las habilidades de los trabajadores, facilitar los intercambios culturales e intelectuales, acentuar la movilidad y profundizar el entendimiento de la diversidad de nuestra región" (APEC, 1993); durante los años posteriores, las instituciones de educación superior de los países asociados en el foro comenzaron a crear los denominados Centros de Estudios APEC, federados en el Consorcio Internacional de Centros de Estudios APEC.

El foro adquirió así la configuración tripartita, propia de los organismos asiáticos de cooperación regional, pero siempre manteniendo la preeminencia del sector gubernamental sobre los de negocios y académico; éstos devinieron la audiencia ante el cual aquél debía rendir cuentas. La administración Clinton cerraba el círculo de la declaración de 1993 afirmando: "estamos comprometidos en la profundización de nuestro espíritu de comunidad, basado en nuestra visión compartida de lograr la estabilidad, la seguridad y la prosperidad de nuestros pueblos" (APEC, 1993).

Las posteriores reuniones de los líderes fueron dando concreción al programa de liberalización comercial y financiera basada en el "regionalismo abierto" y en el sistema multilateral. En la reunión de Indonesia fueron establecidos 2010 y 2020 como las Metas o como los Objetivos de Bogor, entendidos como las fechas para la liberalización comercial y financiera voluntaria y unilateral para las economías avanzadas y para las economías en desarrollo participantes en el foro (APEC, 1994). En la reunión de Japón, la liberalización comercial y financiera fue acompañada con los programas para la facilitación comercial y financiera, así como para la cooperación técnica, constituyendo los "tres pilares de APEC" (APEC, 1995). En la reunión de Filipinas, el Plan de Acción de Manila sentó las bases para el programa de facilitación comercial y financiera, mediante iniciativas nacionales voluntarias denominadas Early Voluntary Sectoral Liberalization (EVSL) e Individual Action Plans (IAPs, APEC, 1996). 


\section{Influencia del contexto global en la transición del "regionalismo abierto" a los acuerdos comerciales regionales}

A partir de 1997, la conjugación de factores regionales y globales influyeron para apagar progresivamente el ímpetu generado por el regionalismo abierto y para transitar hacia la adopción del proyecto del Área de Libre Comercio de Asia Pacífico (ALCAP), es decir, hacia la constitución de un bloque comercial considerado por el GPE como cerrado y como una desviación en la consecución del libre comercio mundial.

En la escala de la región del Pacífico, la crisis asiática y sus efectos sociopolíticos influyeron directamente sobre el abandono parcial del programa de facilitación comercial y financiera. La inacción de los gobiernos anglosajones para afrontar la crisis asiática, movió los asiáticos a suspender la puesta en práctica de la EVSL y a crispar el diálogo durante la reunión de Vancouver, en 1997. El año siguiente, las presiones anglosajonas para utilizar los programas de ajuste estructural del Fondo Monetario Internacional (FMI) como respuesta a la crisis asiática, deslucieron la reunión de Kuala Lumpur. La represión contra los partidarios de la independencia de la provincia indonesia de Timor Timur y la movilización de los gobiernos australiano y neozelandés para organizar una fuerza militar de pacificación, garante del referéndum por la independencia de la provincia indonesia, pusieron en entredicho la reunión de 1999, en Auckland.

En la escala global, las ambigüedades de la política económica internacional del gobierno estadounidense provocaron el abandono de una actitud asiática favorable al multilateralismo, en beneficio de la negociación y puesta en práctica de acuerdos comerciales regionales (ACR). En efecto, desde el final de la Segunda Guerra Mundial, el gobierno estadounidense se había esforzado en consolidar las instituciones multilaterales como mecanismos para contener el progreso del comunismo en la escala global; sin embargo, en 1985, con la firma del Acuerdo de Libre Comercio Estados Unidos-Israel (ALC EU-Israel) comenzó un vaivén permanente entre el multilateralismo del GATT y los ACR:

- En 1987, la tendencia favorable a los ACR fue reforzada con la firma del ALC EUCanadá. 
- En 1990, los gobiernos de Canadá, los Estados Unidos y México anunciaron el inicio de las negociaciones del ALC de América del Norte (ALCAN).

- En 1993, los europeos firmaron el Tratado de Maastrich para la creación del mercado único de la Unión Europea.

- En 1994, con el impulso de la administración Clinton, la I Cumbre de las Américas adoptó un proyecto de integración económica continental que, más tarde, sería nombrado Acuerdo de Libre Comercio de las Américas (ALCA). En 2001, ya bajo la primera administración George W. Bush, la primera versión del ALCA fue difundida parcialmente durante la cumbre de Quebec. En 2002, los negociadores del ALCA acordaron firmar el acuerdo definitivo, en enero de 2005, durante la IV Cumbre de las Américas. En 2005, en Mar del Plata, el gobierno panameño, respaldado por el estadounidense y el mexicano, presentó una moción para continuar con el proceso ALCA; los gobiernos autoproclamados de izquierda de Argentina, Brasil, Paraguay y Venezuela presentaron una moción en contra y el proyecto del ALCA fue desechado (Ramírez Bonilla, 2019).

Ahora bien, las expectativas creadas por el compromiso contraído en la I Cumbre de las Américas reforzaron la incertidumbre generada por el ALCAN y por el mercado único de la Unión Europea, empujando, durante la década de 1990, a los gobiernos americanos y, durante la década de 2000, a los gobiernos del Pacífico asiático a resolver el dilema "multilateralismo o regionalismo", en favor del regionalismo basado en los ACR sancionados por el organismo GATT-OMC.

Después de la entrada en vigor del ALCAN y del Tratado de Maastricht, los miembros de APEC comenzaron a negociar frenéticamente ACR; así, en octubre de 2019, la base de datos de la Organización Mundial de Comercio (OMC) registraba un total de 320 ACR en vigor; en 155 de ellos (48.44\% del total de la OMC) participaban socios de APEC; por tipo de acuerdos, de los 155, 17 (10.97\%) eran multilaterales y siete de ellos involucraban exclusivamente socios de APEC; 138 (89.03\%) eran bilaterales y, de éstos, 48 (30.97\%) eran entre socios de APEC. 
El cuadro 1 muestra otras dimensiones de este proceso por la preferencia de ACR sobre los mecanismos multilaterales de liberalización comercial y financiera. El cuadro muestra el total de ACR bilaterales por país y el número de ACR con contrapartes de APEC. Los acuerdos con socios de APEC son contabilizados dos veces y las sumatorias no coinciden con el total de 155 ACR para todos los socios de APEC. En todo caso, si consideramos que los 21 gobiernos mantienen 186 acuerdos bilaterales en vigor y que, de ésos, 96 han sido firmados con contrapartes de APEC, tenemos una media de 51.61\% de ACR intra-APEC; esta proporción media confirma la realización de los temores del GPE sobre la posibilidad de que APEC deviniese un bloque comercial cerrado.

CuAdro 1. Participación de los miembros de APEC en Acuerdos Comerciales Regionales (hasta octubre de 2019)

\begin{tabular}{|c|c|c|c|c|c|c|c|}
\hline & \multirow{2}{*}{\begin{tabular}{|c|} 
Total \\
$A C R$
\end{tabular}} & \multicolumn{2}{|c|}{ Con socios APEC } & & \multirow{2}{*}{$\frac{\text { Total }}{A C R}$} & \multicolumn{2}{|c|}{ COn socios APEC } \\
\hline & & Subtotal & $\%$ & & & Subtotal & $\%$ \\
\hline Total OMC & 320 & & & & & & \\
\hline Total socios APEC & 155 & & & & & & \\
\hline$\%$ del total OMC & 48.44 & & & & & & \\
\hline Asiáticos del Pacífico & 96 & 54 & 56.25 & Otros del Pacífico & 107 & 49 & 45.79 \\
\hline$\%$ del total OMC & 30.00 & & & $\%$ del total OMC & 33.44 & & \\
\hline Multilaterales & 13 & 6 & & Multilaterales & 4 & 1 & 25.00 \\
\hline ASEAN & 10 & 4 & 40.00 & Comunidad Andina & 1 & & \\
\hline APTA & 1 & & 0.00 & ALADI & 1 & & \\
\hline СРТРР & 1 & 1 & 100.00 & ALCAN & 1 & 1 & 100.00 \\
\hline ТРP & 1 & 1 & 100.00 & Alianza del Pacífico & 1 & & \\
\hline Asia del este & 49 & 30 & & Oceanía & 17 & 16 & 94.12 \\
\hline Japón & 16 & 12 & 75.00 & Australia & 10 & 10 & 100.00 \\
\hline RP China & 14 & 8 & 57.14 & Nueva Zelanda & 5 & 5 & 100.00 \\
\hline Corea del Sur & 13 & 8 & 61.54 & Papúa NG & 2 & 1 & 50.00 \\
\hline Taiwán & 6 & 2 & 33.33 & América & 76 & 31 & 40.79 \\
\hline Asia del sureste & 34 & 18 & & Chile & 23 & 12 & 52.17 \\
\hline Singapur & 12 & 5 & 41.67 & México & 17 & 3 & 17.65 \\
\hline Malasia & 6 & 3 & 50.00 & Perú & 13 & 8 & 61.54 \\
\hline Hong Kong & 5 & 2 & 40.00 & Canadá & 12 & 3 & 25.00 \\
\hline Tailandia & 5 & 3 & 60.00 & Estados Unidos & 11 & 5 & 45.45 \\
\hline Vietnam & 2 & 2 & 100.00 & Rusia & 10 & 1 & 10.00 \\
\hline Indonesia & 2 & 1 & 50.00 & & & & \\
\hline Filipinas & 1 & 1 & 100.00 & & & & \\
\hline Brunéi & 1 & 1 & 100.00 & & & & \\
\hline
\end{tabular}

FuENTE: World Trade Organization, s.f. "Regional Trade Agreements Data Base". Recuperado de http:// rtais.wto.org/UI/PublicAllRTAListAccession.aspX 
Tomando en cuenta la tasa media de ACR intra-APEC como criterio para distinguir, por un lado, Rusia, México, Canadá, Taiwán, Hong Kong, Singapur, Estados Unidos, Malasia, Indonesia y Papúa Nueva Guinea como economías orientadas hacia los mercados extrarregionales, con tasas que van de $10 \%$ a 50\%; las 11 economías restantes registraron tasas oscilantes entre 52.75\% (Chile) y 100\% (Vietnam, Filipinas, Brunéi, Australia y Nueva Zelanda) y pueden ser consideradas como orientadas a favorecer la consolidación del mercado intrarregional, mediante ACR bilaterales. En uno y otro caso, los gobiernos de APEC han mostrado una preferencia por los ACR sobre los mecanismos multilaterales de la OMC, poniendo en entredicho la efectividad de esta instancia multilateral.

\section{El ascenso comercial y político de la República Popular China}

El fracaso de las negociaciones del ALCA y, sobre todo, los atentados suicidas contra las Torres Gemelas del 11 de septiembre de 2001, reorientaron la política exterior estadounidense hacia la "guerra" contra el terrorismo internacional e implicaron un desentendimiento de las administraciones Bush sobre los procesos de integración económica en la región del Pacífico; esa desatención creó un vacío llenado por el gobierno de la RPCh, primero, mediante el ascenso de China como una potencia comercial y, después, a través de iniciativas políticas tendientes a reforzar la influencia china en la región.

\section{El ascenso de China como potencia exportadora}

La gráfica 1 contiene las tasas de participación de los Estados Unidos, Japón y China en las exportaciones y en las importaciones globales de bienes y de servicios, durante 1991-2017; es decir, el periodo comienza con la inclusión de China en APEC y llega hasta nuestros días. El primer aspecto que destaca en la gráfica es la función comercial de China; con frecuencia, los comentaristas afirman que China se ha convertido en la fábrica del mundo (Zhang, 2006) o bien en el motor del crecimiento mundial (Garnault y Song, 2006). Si nos atenemos a los hechos, la economía china disputa a la estadounidense la preponderancia como principal exportadora global; esto permite sostener la afirmación de que China es, más que la fábrica del mundo, una fábrica con proyección global. Sin embargo, si concentramos la atención sobre la participación de ambas economías en las importaciones globales, veremos que, pese 
al progreso chino, la estadounidense aún mantiene una importante ventaja, y ésta, en ese sentido, sigue siendo el principal motor del crecimiento, mientras que aquélla mantiene un carácter secundario como tal. El punto es importante, pues la capacidad de consumo estadounidense es la ventaja competitiva utilizada por la administración Trump para reorganizar el sistema económico global en función de sus intereses y sobre la base de ACR bilaterales.

GRÁFICA 1. Tasas de participación en las exportaciones y en las importaciones globales de bienes y de servicios

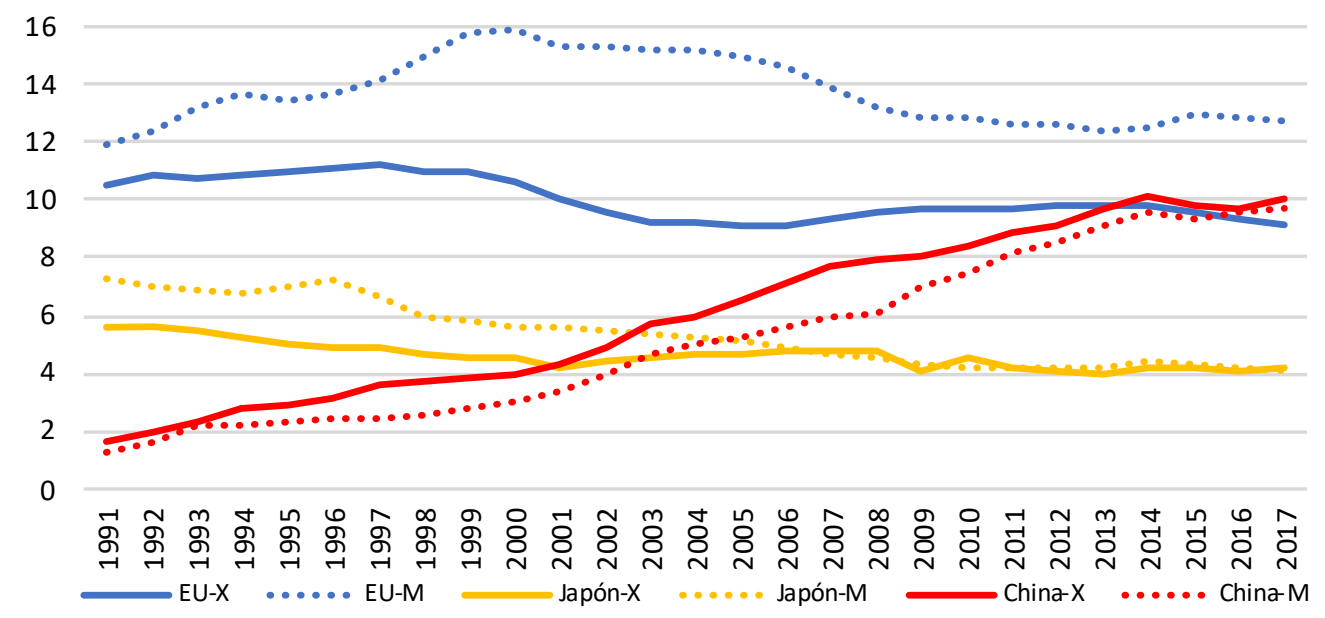

FUENTE: elaboración propia, con información de United Nations Statistics Division, National Accounts, GDP and its breakdown at constant 2010 prices in US dollars https://unstats.un.org/unsd/snaama/downloads

El segundo aspecto relevante de la gráfica 1 son las pendientes de las seis curvas: mientras las dos chinas son siempre positivas, las dos niponas son negativas en permanencia y las dos estadounidenses son negativas a partir de 1997 (exportaciones) y de 2000 (importaciones); por supuesto, en la medida que se trata de participaciones porcentuales en el total global, el progreso de China se refleja de manera directa en los retrocesos de Japón o de los Estados Unidos; pero más allá de esa relación aritmética, las curvas marcan dos momentos clave en la evolución de la economía global:

- 2000-2001, marca el fin de la apertura económica china orientada hacia los chinos de ultramar; durante esta fase, la economía china se consolidó como una potencia comercial regional, superando la japonesa. Ese bienio también marca el inicio de la 
apertura universal, permitiendo el acceso de inversiones extranjeras directas de todos los orígenes geográficos, y el rápido progreso como una potencia comercial global.

- 2013-2014 es la transición hacia un régimen comercial global de carácter dual, marcado por el predominio de las exportaciones chinas y por la preponderancia del mercado estadounidense como principal consumidor global. Como hemos indicado, este tema es clave en la política económica internacional de la administración Trump.

El tercer aspecto destacable en la gráfica es la relación entre exportaciones e importaciones: para los Estados Unidos y Japón, las tasas de las segundas tienden a superar a las de las primeras; es decir, demandan más bienes y servicios de los que ofrecen en el mercado mundial y fungen como motores del crecimiento global. En el caso de China, las tasas de las exportaciones superan siempre las de las importaciones, denotando que consume menos bienes y servicios de los que exporta; en el pasado, esta circunstancia era expresada mediante el término free rider, para señalar aquellas economías que violaban la reciprocidad comercial, para beneficiarse unilateralmente de las relaciones con sus contrapartes. En gran medida, esta idea subyace en los argumentos de la administración Trump para descalificar la inserción global de la economía china.

En resumen, para el gobierno estadounidense, el ascenso económico de China representa un desafío múltiple: en términos económicos, la competitividad del gigante asiático le ha permitido disputar la preponderancia comercial en el campo de las exportaciones; en términos políticos, por primera vez, el contrincante económico es un gobierno independiente de los Estados Unidos y dominado por un partido único que borra los límites entre la economía y la política domésticas y que, además, busca imponer su propia agenda internacional. En efecto, con el progreso en el campo económico, el gobierno chino desarrolló su propia agenda internacional y, en el marco de APEC, ésta se reflejó en diferentes proyectos de integración económica regional, construidos al margen y dentro de la agenda del foro.

\section{Las iniciativas chinas de integración económica en el margen de APEC}

Hemos señalado que el malogrado proyecto del ALCA generó preocupaciones entre los gobiernos asiáticos que se veían excluidos de las preferencias comerciales otorgadas por los 
estadounidenses a sus contrapartes latinoamericanas. Los chinos no fueron la excepción y, mientras los singapurenses entablaban negociaciones con los neozelandeses y con los japoneses, el gobierno chino, en 2000, propuso a los miembros de ASEAN negociar un acuerdo comercial entre los 11 gobiernos; en 2001, durante la cumbre de ASEAN en Brunéi, la propuesta fue aceptada y, a partir de 2002, comenzó el proceso para empezar de inmediato con la organización de un área de libre comercio, cuyo funcionamiento completo estaba programado para 2010 (Ramírez Bonilla, 2006).

La iniciativa sino-aseanense perturbó las estrategias del resto de los gobiernos de Asia Pacífico, basadas, hasta entonces, en la negociación de acuerdos bilaterales de gobierno a gobierno; así, en 2003, los gobiernos japonés e indio también comenzaron la creación de las condiciones políticas para firmar un acuerdo comercial con los integrantes de ASEAN; en 2004, fue el turno del gobierno surcoreano de sumarse a los acuerdos con la ASEAN; en 2009, los gobiernos de Australia y Nueva Zelanda también se movieron en la misma dirección, para firmar un acuerdo comercial entre los 12 gobiernos; finalmente, ese último año, los gobiernos de ASEAN y de la India culminaron las negociaciones iniciadas en 2003.

En 2006, sobre la base de los acuerdos comerciales centrados sobre la ASEAN, el gobierno japonés propuso una iniciativa de integración regional denominada Comprehensive Economic Partnership for East Asia (CEPEA) que incluía los 10 gobiernos de la ASEAN y los de Australia, China, Corea, India, Japón y Nueva Zelanda. En 2009, durante las reuniones de ASEAN, el proyecto fue incluido en la agenda de la asociación. Mientras los japoneses se esforzaban en interesar a sus socios en un proyecto basado en una negociación sectorial compleja entre 16 gobiernos, los chinos, con el apoyo de los gobiernos de la ASEAN, avanzaron su peón: el Regional Comprehensive Economic Partnership (RCEP), que incorporaba los mismos 16 gobiernos que el CEPEA, pero que suponía una negociación expedita, basada en la experiencia del ALC ASEAN-China. La ASEAN incorporó el proyecto en la agenda de las reuniones cumbre, en noviembre de 2011, y la negociación no ha sido ni rápida ni tersa; de mayo de 2013 a julio de 2019 han sido llevadas a cabo 27 rondas de negociaciones, sin haber llegado a un acuerdo definitivo (Wikipedia, s.f.a.). 


\section{La iniciativa china de integración económica en el marco de APEC}

Mientras los gobiernos participantes en APEC se lanzaban en una carrera frenética por firmar acuerdos para compensar las desventajas de los convenios comerciales promovidos por las grandes potencias económicas, en el foro mismo mantenían una actitud conservadora, apegándose estrictamente al guión definido durante 1993-1996: "la consecución de las metas que definimos en Bogor” y "la primacía del sistema comercial multilateral”. Así, en 2003, los líderes económicos todavía consideraban que la Ronda de Doha “ofrece el potencial para progresos reales para todas las economías, particularmente las economías en desarrollo, en áreas como la reforma agrícola, el mejoramiento del acceso al mercado para bienes y servicios, así como la clarificación y el mejoramiento de las disciplinas comerciales" (APEC, 2003). Sin embargo, para entonces, los representantes del sector privado asociados en ABAC fueron sensibilizados por la ola de ACR negociados por y entre participantes del foro; los empresarios se mostraron receptivos al estudio de factibilidad sobre un área de Libre Comercio de Asia-Pacífico, realizado por académicos participantes tanto en los APEC Study Centers, como en el Pacific Economic Cooperation Council (PECC); así, en la Declaración de los Líderes de 2004, por primera vez mencionaban el proyecto de un área de libre comercio propia de los integrantes del foro; en un breve párrafo mencionaban que "ABAC nos presentó dos propuestas relevantes: un estudio de alcance conjunto para una Agenda Trans-Pacífica de Negocios y un estudio sobre la factibilidad, el alcance potencial y las características de un Área de Libre Comercio de Asia-Pacífico" (ALCAP, APEC, 2004).

En 2005, los líderes volvieron a formular las referencias rituales a las Metas de Bogor y a los compromisos con el sistema multilateral; sin embargo, en su declaración, introdujeron el tema de los acuerdos comerciales regionales:

Acordamos que los ACR/ALC (Acuerdos Comerciales Regionales/Acuerdos de Libre Comercio) de alta calidad son vías importantes para lograr el comercio y la inversión libres y abiertos, y solicitamos un trabajo continuo para lograr alta calidad, transparencia y una amplia consistencia en los ACR/ALC en la región. También acogemos con beneplácito las Medidas del Modelo de Facilitación del Comercio de APEC para los ACR/ALC que servirían como una referencia significativa para la negociación de los ACR/ALC y solicitamos el 
desarrollo de medidas modelo para la mayor cantidad posible de capítulos de ALC comúnmente aceptados (APEC, 2005).

Los líderes se concebían como árbitros de la calidad de los ACR y aceptándolos, por primera vez, se apartaban del regionalismo abierto propuesto por el GPE y los sustituían por los ACR, entendidos contradictoriamente "como vías para lograr el comercio y la inversión libres y abiertos".

A lo largo de 2006-2009, los gobiernos asociados en APEC dedicaron su atención a evaluar las posibilidades del proyecto del ALCAP; mientras tanto, en febrero de 2008, la segunda administración George W. Bush solicitaba la adhesión al Trans-Pacific Strategic Economic Partnership Agreement (TPSEP o TPP-4), firmado por los gobiernos de Brunéi, Chile, Nueva Zelanda y Singapur, en 2005. Con la incorporación sucesiva de los gobiernos de Australia, Perú y Vietnam (2008), de Malasia (2010), de Japón (2011), así como de Canadá y México (2012), la primera administración de Barack Obama convirtió la adhesión de los Estados Unidos al TPP-4 en la negociación de un nuevo acuerdo comercial (conocido como el Trans-Pacific Partnership Agreement - TPP o TPP-12 - y, como veremos en la sección subsiguiente, en uno de los instrumentos del "giro hacia el Pacífico" para aislar al gobierno chino.

En ese contexto y ante la incapacidad de rendir cuentas positivas en relación con la liberalización unilateral, voluntaria y universal de las economías avanzadas de APEC, como estipulaban las Metas de Bogor, en 2010, los líderes optaron por incluir la propuesta del ALCAP como un "instrumento mayor para promover la agenda de integración económica regional de APEC" e indicaban que "se debe buscar un ALCAP como un acuerdo integral de libre comercio, mediante el desarrollo y la construcción de compromisos regionales en curso como ASEAN+3, ASEAN+6 y el TPP, entre otros" (APEC, 2010). Así, mientras los integrantes del GPE consideraban que, en el marco del regionalismo abierto propuesto por ellos, los ACR no eran sino escollos (stumbling blocks) en el camino de la liberalización unilateral y voluntaria, los líderes pasaron a considerarlos bloques constructivos (building blocks), pues éstos, como un rompecabezas, permitirían alcanzar la liberalización comercial y financiera, pero en un bloque cerrado. 
Pese a que, como señalamos, en 2011, la ASEAN dio existencia formal al proyecto del RCEP impulsado por ella y por el gobierno chino, la iniciativa no fue mencionada en las declaraciones de ese año ni en las de los subsecuentes; las autoridades chinas, en consecuencia, debieron esperar hasta 2015 para tomar una revancha política que sorprendió a todos en APEC: siendo las anfitrionas de la reunión de líderes, incluyeron en la agenda el documento The Beijing Roadmap for APEC's Contribution to the Realization of the FTAAP. En él, el gobierno chino delineó seis principios fundamentales que debían ser preservados durante la construcción del ALCAP; de ellos, nos interesan particularmente los cinco primeros:

El sistema de comercio multilateral, basado en normas, seguirá siendo un principio clave de APEC. El ALCAP debe construirse sobre la base del apoyo y el complemento del sistema multilateral de comercio.

El ALCAP deberá hacer más que lograr la liberalización en su sentido estricto [...]

Alcanzar los objetivos de Bogor en 2020 seguirá siendo el objetivo central de APEC, y el progreso realizado para alcanzar esos objetivos permitirá avanzar sustancialmente y ayudará a determinar la contribución de APEC a la eventual realización del ALCAP (APEC, 2015).

Hasta aquí, el Beijing Roadmap se limita a cumplir con el ritual de privilegiar el sistema multilateral y los Objetivos de Bogor, aun cuando el primero de ellos no había sido alcanzado. Sin embargo, el cuarto principio vino a sacudir la inercia en que se habían instalado los líderes del foro:

El ALCAP será realizado fuera de APEC, en paralelo con el proceso de APEC. APEC debe mantener sus principios de cooperación voluntaria no vinculantes, en sus contribuciones a la realización del ALCAP. APEC alentará una mayor liberalización y reforma unilateral del comercio y de la inversión, continuará desempeñando un papel como incubadora del ALCAP y proporcionará liderazgo y aportes intelectuales para su realización (APEC, 2015).

La propuesta china despejó las dudas en torno al futuro de APEC; pues, hasta entonces, no era claro si, al instituir el ALCAP, el foro habría de transformarse en un área de libre comercio. Para los chinos, APEC debería seguir como un foro de cooperación económica, con sus características propias en materia de negociaciones; por eso, el ALCAP debía ser llevado 
a cabo al margen de APEC, pero como una iniciativa del foro. Las autoridades chinas mostraban haber comprendido el papel de APEC como un mecanismo para la "contención sin aislamiento" de un gobierno estadounidense preocupado por la creciente influencia china. Más allá de eso, la propuesta de alentar una mayor liberalización y reforma unilateral del comercio y de la inversión volvía a ser formulada como un deseo piadoso, imposible de ser realizado en un contexto marcado por las preferencias por los ACR.

En el quinto principio, el gobierno chino volvía a poner de realce los ACR en curso en la región del Pacífico como bloques constructivos:

El ALCAP debe apuntar a minimizar los efectos negativos resultantes de los ACR/ALC regionales y bilaterales; y se buscará construirlo sobre las arquitecturas regionales actuales y en desarrollo. Se deben realizar mayores esfuerzos para concluir las posibles vías hacia el ALCAP, incluidos el TPP y el RCEP (APEC, 2015).

Por fin los chinos veían coronados sus esfuerzos políticos regionales, introduciendo el tema del RCEP, junto al TPP, en la declaración de líderes dictada por ellos. La introducción del tema es significativa por dos razones: por una parte, por primera vez, los dos proyectos en competencia y tendientes a excluir a la contraparte promotora de la otra iniciativa eran considerados bases para el ALCAP. Por otro lado, se trató de la primera iniciativa política china, tendiente a incluir en la agenda de APEC su propio proyecto de integración regional y a disputar la influencia política a los Estados Unidos, cuando menos, en la región asiática del Pacífico.

\section{Hillary Clinton vs. William Clinton}

Como hemos visto, en APEC, la transición de la primera a la segunda década del siglo XXI estuvo marcada por la consolidación de China como una economía con proyección global y por la confianza del gobierno chino en sus propios recursos para incrementar tanto su influencia política en Asia del Pacífico, como su proyección en toda la región del Pacífico. Para la primera administración Obama (2009-2013), el momento político creado por la solicitud de su predecesora para incorporarse al TPP-4 fue utilizado como un instrumento para 
aislar económicamente a su contraparte china. Después de concluidas las negociaciones del TPP, la Casa Blanca justificaba el acuerdo de la siguiente manera:

[...] en este momento, nuestra política comercial —el statu quo - pone a nuestros trabajadores y empresas en desventaja, con costos más altos para los productos estadounidenses, más barreras para el comercio y estándares más bajos para los trabajadores y el medio ambiente en el extranjero que en nuestro país.

Es por eso que el presidente Obama ha concluido la negociación de la Asociación Transpacífica (Trans-Pacific Partnership) y ahora trabajará en el Congreso para asegurar su aprobación. El TPP es un acuerdo comercial con otros 11 países de Asia-Pacífico, incluidos Canadá y México, que eliminará más de 18000 impuestos que varios países aplican a los productos hechos en América.

Con el TPP podemos reescribir las reglas del comercio para beneficiar a la clase media de los Estados Unidos. Porque si no lo hacemos, los competidores que no comparten nuestros valores, como China, intervendrán para llenar ese vació (The White House, President Barack Obama, s.f.).

Más allá de la virulencia del discurso de Donald Trump, en el fondo, encontramos en la propuesta de la Casa Blanca de Barack Obama los mismos temas: el aprovechamiento del statu quo por parte de los competidores de los Estados Unidos para obtener ventajas comerciales, la eliminación de barreras comerciales para facilitar el acceso de los productos estadounidenses a los mercados de los socios en el TPP y, para los fines de nuestro trabajo, el establecimiento de nuevos estándares comerciales inalcanzables para y, en consecuencia, excluyentes de China. En este último sentido, un analista singapurense señalaba que "en el corto plazo, es más probable que China mantenga su distancia del TPP”. Las razones aducidas y generalmente aceptadas eran que China "no está lista para poner en práctica las obligaciones que se negocian [en el TPP]. Por el contrario, China esperará para preparar su economía nacional antes de considerar el acuerdo comercial de 'alta calidad integral"; todavía más, el observador sugería que, durante ese compás de espera, China fortalecería sus posiciones en Asia del Pacífico mediante los ALC con Corea y con Japón-Corea (Das, 2013).

La administración Obama, por primera vez en la historia de las relaciones sinoestadounidenses, tomaba distancia de la política de "contención sin aislamiento" de China, 
para aislarla económicamente, mediante un ACR que modificaría las reglas comerciales hasta entonces avaladas por la OMC. Dicho sea de paso, el impacto del contenido del TPP sobre el funcionamiento de la organización comercial mundial no cristalizó, y el riesgo potencial pasó inadvertido para los comentaristas internacionales. Pero, de nueva cuenta, Donald Trump habría de volver a cosechar sobre el terreno sembrado por la administración Obama.

En noviembre de 2011, la Reunión de Líderes estaba programada en Honolulú, Hawái, y Barack Obama pretendía firmar el TPP definitivo; los múltiples desacuerdos sectoriales impidieron cumplir con ese cometido y, por el contrario, los gobiernos de Canadá, México y Canadá manifestaron su deseo de incorporarse al grupo de negociadores, postergando sine die la firma del acuerdo definitivo.

Sin embargo, en vísperas de la reunión, la secretaria de Estado, Hillary Clinton, publicó su controvertido artículo “America’s Pacific Century” (2011); en él, proponía concentrar la atención política del gobierno estadounidense sobre Asia-Pacífico, una región entendida por ella de manera diferente y con la cual la primera administración Obama pretendía revisar la relación con sus aliados históricos. La secretaria de Estado comenzaba definiendo la región:

Asia-Pacífico se ha convertido en un impulsor clave de la política global. Extendiéndose desde el subcontinente indio hasta las costas occidentales de las Américas, la región abarca dos océanos, el Pacífico y el Índico, que están cada vez más vinculados por la navegación y por la estrategia $[\ldots]$ Es el hogar de varios de nuestros aliados clave e importantes potencias emergentes como China, India e Indonesia (Clinton, 2011).

Es imposible pedir precisión geográfica a un político, pues éste percibe el mundo en función de intereses y no de definiciones; el punto es importante, pues a diferencia de la ASEAN que, desde los 1990, consideraba Asia-Pacífico como una región integrada por todo el continente asiático y toda la región del Pacífico (cubriendo las vertientes asiática y americana, así como Oceanía), la secretaria de Estado limitaba su definición a un área extendida desde la península india hasta el continente americano. Más adelante, veremos que, en el ámbito de las definiciones geográficas, Donald Trump se ha limitado a repetir a Hillary Clinton. En todo caso, para nuestros fines, interesa la apreciación de la secretaria de Estado 
sobre la función de Asia-Pacífico como un "impulsor clave de la política global”, pues la estrategia propuesta mediante su texto implica la reconstrucción de las relaciones intergubernamentales con los "aliados clave" con el fin de aislar políticamente a China. Para alcanzar esa finalidad, la secretaria Clinton proponía seis líneas de acción:

- Fortalecer las alianzas bilaterales de seguridad, con aliados históricos como Japón, Corea del Sur, Australia, Filipinas y Tailandia, en primer término; pero también con nuevos socios como China, India, Indonesia, Singapur, Nueva Zelanda, Malasia, Mongolia, Vietnam, Brunéi y los países insulares del Pacífico.

- Profundizar las relaciones de trabajo con potencias emergentes; China ocupa el mayor espacio dedicado a un país en particular y destaca la iniciativa del Diálogo Estratégico y Económico, el cual implica "las conversaciones más intensivas y expansivas entre nuestros gobiernos, que reúnen a docenas de agencias de ambas partes para discutir nuestros asuntos bilaterales más apremiantes, desde la seguridad hasta la energía y los derechos humanos".

- Comprometerse con instituciones multilaterales regionales, como ASEAN (mediante la firma del Tratado de Paz y de Amistad, así como la participación en proyectos subregionales, como la Iniciativa del Bajo Mekong, en colaboración con Camboya, Laos, Tailandia y Vietnam) y APEC (mediante la segunda negociación del ALC CoreaEU, o las negociaciones del TPP).

- Expandir el comercio y la inversión, mediante el TPP.

- Reforzar la presencia militar, extendiéndola más allá de las tropas estacionadas en Japón y Corea, para mejorarla en el sureste de Asia y en el Océano Índico.

- Promover la democracia y los derechos humanos, en Vietnam, Myanmar, Corea del Norte.

La referencia al intricado sistema bilateral sino-estadounidense y el siguiente pasaje podrían mover los lectores a un equívoco sobre el objetivo último de la política con respecto a China: 
En la medida en que construimos confianza juntos, estamos comprometidos a trabajar con China para abordar problemas críticos, regionales y globales, de seguridad. Por eso, me he reunido con frecuencia, y a menudo en entornos informales, con mis homólogos chinos [...], para discusiones sinceras sobre desafíos importantes como Corea del Norte, Afganistán, Irán y los acontecimientos en el Mar del Sur de China (Clinton, 2011).

En efecto, parecería que la finalidad sería construir lazos de cooperación con China; sin embargo, esa apariencia oculta el hecho de que, por primera vez, el gobierno estadounidense se enfrentaba a un adversario capaz de desafiarlo en múltiples áreas económicas, tecnológicas y políticas, pero sin estar en condiciones de suplantarlo como hegemón global. Por ello, la situación era ambigua: por un lado, el aislamiento de China constituía el espíritu de las seis líneas de acción; pero, por el otro, la administración Obama ponía de realce la cooperación bilateral, como un medio de control y de vigilancia sobre su contraparte china, sin parar mientes en que se trataba de un mecanismo de control y de vigilancia recíprocos.

Esa ambigüedad también se reflejó en el texto de la Declaración de los Líderes Económicos de APEC de 2011 (APEC, 2011); la administración Obama comenzó haciendo una breve referencia a la reunión de 1993, recordando que "los líderes de APEC saludaron que Asia-Pacífico haya levantado la voz en la economía global" y pasando de inmediato a la mención ritual de las Metas de Bogor, del compromiso con el sistema comercial multilateral y del ALCAP "como un instrumento mayor para fortalecer la agenda de APEC sobre integración económica regional”. Las iniciativas regionales de integración económica fueron evacuadas del discurso y, por supuesto, ya no hubo ninguna referencia a la Comunidad de Asia Pacífico, propuesta por William Clinton.

El tándem Obama-Clinton cerró así el círculo de la política estadounidense basado en el intento de modelar, de acuerdo con los intereses estadounidenses, una comunidad del Pacífico, para replegarse sobre la redefinición de los intereses nacionales estadounidenses en el marco de una economía regional y global, en la cual las unidades nacionales son cada vez más interdependientes. Esa redefinición implicó el abandono del proyecto de una comunidad del Pacífico, a costa de adoptar una actitud un tanto ambigua respecto a la necesidad de 
excluir la economía china de los proyectos tendientes a reafirmar las funciones estadounidenses en la región.

\section{La administración Trump y la confrontación sino-estadounidense en el seno de APEC}

La aparición de Donald Trump en la escena política estadounidense puso fin a las ambigüedades sobre la necesidad de reconstruir la relación con China, pasando de la búsqueda del aislamiento económico y político a la confrontación directa con el gobierno chino. En ese sentido, el discurso de campaña, pronunciado el 28 de junio de 2016, en Monessen, Filadelfia, es clave para entender la agenda de la política internacional de la administración Trump (Trump, 2016). En términos formales, el discurso contenía sendas acusaciones, infundadas por regla general, contra Hillary Clinton, su rival en la carrera presidencial; la señalaba, junto con su marido, de haber promovido el Área de Libre Comercio de América del Norte (ALCAN), la entrada de China en la OMC, el Acuerdo de Libre Comercio con Corea del Sur y el TPP.

En sentido estricto, el ALCAN fue obra del presidente republicano George Bush, aunque fue firmado por William Clinton. Por otra parte, en 1986, China fue aceptada como observador en el GATT, con el beneplácito de Donald Reagan, entonces presidente de los Estados Unidos y, en diciembre de 2001, durante la presidencia de George W. Bush, China fue aceptada como miembro de la OMC (WTO, 2001). En relación al ALC Corea-EU, cabe decir que su primera negociación fue llevada a cabo y firmada, en abril de 2007, por la administración George W. Bush; ésta jamás sometió el acuerdo a la ratificación por el Congreso y los coreanos debieron esperar la iniciativa de la administración Obama para negociarlo por segunda vez y verlo entrar en operación en marzo de 2012. El TPP, como vimos, también fue una decisión de la administración George W. Bush, y la administración Obama se encontró con un instrumento que habría de utilizar para reformular la política estadounidense sobre China.

Las acusaciones contra la pareja Clinton y particularmente contra Hillary Clinton son, en el mejor de los casos, medias verdades que tuvieron fuertes repercusiones sobre las preferencias electorales de sectores sociales inconformes con la política económica internacional seguida tanto por republicanos, como por demócratas. En todo caso, el principal 
valor del discurso de Monessen es programático; en efecto, Trump consideraba que la política económica internacional dejó de promover el desarrollo de los Estados Unidos "para promoverlo en otras naciones" y que los problemas económicos de la sociedad estadounidense "no son un desastre natural, sino un desastre creado por los políticos"; para superar las dificultades experimentadas por los Estados Unidos, el candidato Trump proponía siete medidas:

1. Retirar a los Estados Unidos del TPP.

2. Nombrar negociadores comerciales estrictos e inteligentes, para luchar en nombre de los trabajadores estadounidenses.

3. Asignar al secretario de Comercio la identificación de cada violación de los acuerdos comerciales, utilizada por gobiernos extranjeros para lastimar a los trabajadores estadounidenses.

4. Notificar a los socios en el ALCAN la intención de renegociar inmediatamente los términos del acuerdo y, si no aceptaran, recurrir al artículo 2205 del ALCAN, para avisarles la intención de retirarse del acuerdo.

Una vez ungido como presidente de los Estados Unidos, Donald Trump cumplió escrupulosamente estos cuatro primeros puntos; ahora bien, para los fines de nuestro trabajo, interesan particularmente la tercera medida y las tres restantes, pues tenían como objetivo último la confrontación directa con China:

5. Instruir al secretario del Tesoro para calificar al gobierno chino como un manipulador de [su] moneda.

6. Instruir al representante comercial de EU para presentar casos comerciales contra China, tanto en los Estados Unidos como en la OMC.

7. Usar las capacidades legales del presidente para remediar las disputas comerciales con China, incluyendo la aplicación de tarifas de acuerdo con las secciones 201 y 301 de la Ley Comercial de 1974 y la sección 232 de la Ley de Expansión Comercial de 1962 (Trump, 2016). 
Los puntos 3, 6 y 7 interesan particularmente pues constituyen el marco de la guerra comercial sino-estadounidense, iniciada el 7 de febrero de 2018, cuando la administración Trump decidió imponer tarifas de 30\% y 20\% sobre las importaciones de paneles solares y de lavadoras de ropa, provenientes de todos los países, con excepción de los paneles solares de origen canadiense. El 22 de marzo de ese año, Trump firmó un memorando con tres medidas dirigidas contra China: $a$ ) presentar un recurso ante la OMC contra China por sus "prácticas discriminatorias en materia de autorizaciones"; $b$ ) restringir las inversiones en sectores tecnológicos clave; c) imponer tarifas sobre productos chinos de los sectores aeroespacial, tecnologías de la información y de la comunicación, maquinaria. El 2 de abril, las autoridades chinas respondieron imponiendo tarifas (entre 15 y 25\%) sobre frutas, vinos, tubos de acero sin costura, carne de cerdo y aluminio reciclado, provenientes de los Estados Unidos, y por un valor total de 2000 millones de dólares (China Briefing, 2019).

Así comenzó la escalada en la guerra comercial que dura hasta el momento de escribir estas líneas y que ha fragilizado una economía global al borde de la recesión. Cierto, ambos gobiernos han recurrido a la OMC para legitimar algunas de las medidas contra el contrincante, pero es necesario reconocer que el organismo multilateral ha sido impotente para contener a los dos gobiernos y, hoy más que nunca, ha quedado al margen de la confrontación política comercial, poniendo en evidencia su inoperancia.

APEC, pese a su naturaleza como foro de diálogo y de consulta para temas de cooperación intergubernamental, cuyas recomendaciones carecen de obligatoriedad para sus participantes, también se convirtió en un escenario de confrontación, mostrando la apremiante necesidad de la administración Trump de recuperar el terreno político perdido ante el gobierno chino. En efecto, como veremos a continuación, la administración Trump se ha empeñado en reconfigurar el programa de cooperación para confrontar a China, pero también ha crispado su relación con los miembros del foro por oponerse a las propuestas para reformar la OMC, con el fin de hacerla más transparente, dotarla de un marco no discriminatorio para la liberalización comercial progresiva, y promover el comercio sobre reglas acordadas por sus miembros (APEC, 2018). 


\section{La administración Trump y el programa de cooperación en APEC}

La Declaración de los Líderes de 2017 (APEC, 2017) fue redactada en el más puro formalismo de APEC, respetando las referencias rituales a las contribuciones del foro a la integración económica en Asia Pacífico, a los compromisos con las Metas de Bogor y a la realización del ALCAP. Una mención particular merece la referencia al compromiso colectivo para mejorar el funcionamiento de la OMC, en la medida en que fue formulada en el marco de la imposición de tarifas arancelarias a los productos importados por los Estados Unidos y la renegociación de los acuerdos comerciales con sus principales contrapartes, todo esto en un contexto marcado por la violación estadounidense de las reglas comerciales de la organización. En ese sentido, los parágrafos 20 y 21 de la declaración estipulaban:

20. Subrayamos el papel crucial de APEC para apoyar un sistema comercial multilateral basado en reglas, libre, abierto, justo, transparente e inclusivo. Nos comprometemos para trabajar juntos en el mejoramiento de la operación de la OMC, incluidas sus funciones de negociación, monitoreo y solución de controversias [...] Trabajaremos para garantizar la aplicación efectiva y oportuna de las normas de la OMC.

21. Señalamos la importancia de los acuerdos [comerciales] bilaterales, regionales y plurilaterales, y nos comprometemos a trabajar para garantizar que complementen los acuerdos comerciales multilaterales (APEC, 2017).

Se trataba de dos medidas defensivas tendientes a recurrir a la OMC para tratar de influir sobre la política económica internacional estadounidense, la cual, ya para entonces, se situaba al margen de la reglamentación de la organización, con la imposición de tarifas arancelarias a las importaciones de los Estados Unidos y con la renegociación de los acuerdos comerciales sobre la base de la bilateralidad y de la coerción para imponer el interés estadounidense (Ramírez Bonilla, 2019).

Fuera de esos dos parágrafos, la declaración de 2017 se apegaba al formalismo de todas las declaraciones precedentes y, por sí misma, podía llevar a apreciar equívocamente la confrontación política entre representantes chinos y estadounidenses. En efecto, para completar el panorama de la reunión de 2017, es necesario recurrir al discurso pronunciado 
por Donald Trump ante el APEC CEO Summit, del 10 de noviembre de ese año. El discurso es relevante por los tres aspectos siguientes:

Primero, Trump comenzaba forzando una nueva definición del área geopolítica de interés para su gobierno, abandonando la denominación Asia-Pacífico para acuñar el término Indo-Pacifico: "he tenido el honor de compartir nuestra visión para una [región] IndoPacífico libre y abierta, un lugar donde naciones soberanas e independientes, con culturas diversas y muchos sueños diferentes, pueden prosperar en conjunto, en libertad y en paz" (Trump, 2017).

Trump, como en el pasado los representantes chinos ante APEC, se esforzó en marcar con su discurso la jerga utilizada en el foro; con el término Indo-Pacífico ampliaba la cobertura geográfica de su interés, para incluir a la India como un factor de contrapeso a la influencia china en el extremo oriental de Asia. La propuesta parecía novedosa; sin embargo, como señalamos antes, Hillary Clinton, en 2011, ya había recurrido al mismo expediente al formular el giro de la administración Obama hacia el Pacífico.

Segundo, como Nixon, en 1967, y Hillary Clinton, en 2011, Trump hizo referencia a los éxitos económicos y los progresos realizados por Filipinas, Tailandia, Malasia, Singapur, Corea y China; sin embargo, para justificar su elección por la denominación Indo-Pacífico, se vio compelido a mencionar India, como "la más grande democracia en el mundo. Desde que India abrió su economía, ha logrado un sorprendente crecimiento y un nuevo mundo de oportunidades para su creciente clase media"; y, para concluir su introducción, señalaba que todos esos países "han seguido proyectos de justicia y responsabilidad, promovido la propiedad privada y el estado de derecho, y adoptado sistemas que valoran el trabajo arduo y la empresa individual" (Trump, 2017). De nueva cuenta, como Nixon y la señora Clinton, Trump proyectaba las instituciones estadounidenses como la causa eficiente de los progresos realizados por los gobiernos de Asia del Pacífico; pero nótese que, con ellos, hilvanaba su discurso, preparando la audiencia para escuchar las andanadas contra la OMC y contra el gobierno de la República Popular China.

Tercero, a diferencia de sus antecesores y recurriendo al contexto multilateral de la OMC, Trump presentaba la economía estadounidense como víctima de los abusos permitidos 
por el modus operandi de la organización y, sin mencionarlo directamente, por el gobierno chino; por ello, abogaba por un cambio drástico en el statu quo:

La OMC acogió a los países, incluso si no cumplían con sus principios establecidos. En pocas palabras, la OMC no nos ha tratado de manera justa. Organizaciones como la OMC sólo pueden funcionar correctamente cuando todos los miembros siguen las reglas y respetan los derechos soberanos de cada miembro. No podemos lograr mercados abiertos si no garantizamos un acceso justo al mercado.

Al final, el comercio injusto nos debilita a todos. Los Estados Unidos promovieron las empresas privadas, la innovación y la industria. Otros países utilizaron la planificación industrial dirigida por el gobierno y empresas estatales.

Aceptamos los principios de la OMC sobre la protección de la propiedad intelectual y la garantía de un acceso justo e igualitario al mercado.

Ellos se dedicaron al dumping de productos, a subsidiar productos, a manipular divisas y [poner en práctica] políticas industriales depredadoras.

Ignoraron las reglas para obtener ventaja sobre aquellos que las siguieron, causando enormes distorsiones en el comercio y amenazando los fundamentos del comercio internacional.

Tales prácticas, junto con nuestra incapacidad colectiva para responder a ellas, perjudicaron a muchas personas en nuestro país y en otros. Además, en los Estados Unidos y muchos países, fueron eliminados empleos, fábricas e industrias. Se perdieron muchas oportunidades para inversiones mutuamente beneficiosas, porque la gente no podía confiar en el sistema.

Ya no podemos tolerar estos abusos comerciales crónicos y no los toleraremos. A pesar de años de promesas incumplidas, nos dijeron que algún día, pronto, todos se comportarían de manera justa y responsable. Las personas en los Estados Unidos y en toda la región Indo-Pacífico han esperado que llegue ese día. Pero ellos nunca lo han hecho y, por eso, estoy aquí para hablar francamente sobre nuestros desafíos y trabajar para un futuro mejor para todos nosotros (Trump, 2017).

Los lectores perdonarán la extensión de la cita, pero contiene detalles que revelan dos ejes de la política económica internacional de la administración Trump: por un lado, la reforma de la OMC, para ajustarla a la concepción de Trump sobre el cumplimiento de la ley; en este marco, la ley es entendida no como un derecho igual para todos sino como el derecho 
a imponer los intereses particulares de los Estados Unidos a los otros; el cumplimiento de la ley es, en consecuencia, el respeto de los intereses estadounidenses; así, la OMC tiene razón de ser sólo si sanciona la imposición de los intereses estadounidenses. Ante las veleidades trumpianas sobre una reforma de la OMC acorde con los intereses estadounidenses, no es extraño que los Líderes Económicos de APEC hayan incluido los parágrafos 20 y 21 en su Declaración de 2017.

El segundo eje de la política internacional de la administración Trump es evidente: el gobierno chino es el blanco directo de todos los juicios sobre el funcionamiento del sistema multilateral; ante el "mal" funcionamiento de la OMC, Trump pone de realce el tercer eje de su política económica internacional: el abandono del multilateralismo, para reconstruir las relaciones con los socios más relevantes sobre la base del bilateralismo; un bilateralismo donde la asimetría garantiza al gobierno estadounidense la preponderancia sobre cualquiera de sus contrapartes. Trump expone su conclusión política de la manera siguiente:

A partir de este día, competiremos de manera justa y equitativa. No vamos a permitir que se aproveche más de los Estados Unidos. Siempre voy a poner a los Estados Unidos primero; de la misma manera, espero que todos ustedes [...] pongan a sus países primero.

[...] Haré acuerdos comerciales bilaterales con cualquier nación del Indo-Pacífico que quiera ser nuestro socio y que cumpla con los principios del comercio justo y recíproco. Lo que ya no haremos es celebrar grandes acuerdos que nos aten de manos, que nos hagan renunciar a nuestra soberanía y que tornen prácticamente imposible su aplicación plena (Trump, 2017).

La renuencia a suscribir grandes acuerdos debe ser entendida en un sentido amplio, para incluir tanto la OMC, como ACR multilaterales del tipo del ALCAN, el TPP y el ALCAP. Como veremos a continuación, la ofensiva trumpiana contra la OMC y la defensa de la misma por el resto de los socios de APEC provocaron la parálisis política en las reuniones ministeriales y de líderes de 2018. 
La administración Trump: de la censura sobre las propuestas de APEC para reformar la OMC a la confrontación directa con el gobierno chino

La Reunión de los Líderes Económicos de APEC de 2018, en Port Moresby, Papúa Nueva Guinea, ha sido la más deslucida y problemática en toda la historia del foro. Para comenzar, los observadores internacionales citaban la difícil situación económica y social del país anfitrión, poniendo de realce los problemas de logística que planteaba para los jefes de Estado y de gobierno la asistencia a las reuniones. En segundo término, los jefes de Estado de los Estados Unidos, México, Perú, Rusia y Vietnam faltaron a la cita (Wikipedia, s.f.b.) y las ausencias fueron vistas como un desaire al gobierno papuense; pero, con la distancia temporal, también pueden ser interpretadas como un síntoma de la parálisis política del foro. Finalmente, las diferencias entre el vicepresidente Pence y sus contrapartes chinas, pero también entre el mismo vicepresidente y el resto de los representantes gubernamentales, por primera vez en la historia de las reuniones de jefes de Estado y de gobierno, impidieron llegar a un consenso sobre el texto final de la declaración oficial, y el gobierno local debió contentarse con un Pronunciamiento de la Presidencia de la reunión de 2018 (APEC, 2018b).

En términos formales, el Pronunciamiento cubrió todas las referencias rituales de APEC al compromiso con las Metas de Bogor, a los progresos realizados en la senda del ALCAP y al mejoramiento del modus operandi de la OMC. Con respecto a este último punto, el parágrafo 17 del Pronunciamiento fue lacónico: "Para mejorar el funcionamiento de la OMC y cumplir con todos sus miembros, nos comprometemos a trabajar juntos para mejorar sus funciones de negociación, monitoreo y solución de controversias. También alentamos las economías de APEC para incrementar su participación en la OMC, para mejorar su trabajo” (APEC, 2018b). Ese laconismo, sin embargo, contrasta con los cinco parágrafos (7 a 11) dedicados a la OMC en la declaración de la Reunión Ministerial de 2018 y, sobre todo, explica la renuencia de los representantes estadounidenses para suscribir una Declaración de los Líderes que no respondía a su política con respecto a la organización:

7. Reconocemos la importancia de trabajar para lograr mercados libres y abiertos, del comercio internacional y de la inversión para brindar prosperidad a nuestra gente. Apoyamos un buen funcionamiento de la OMC que proporcione un marco transparente y no 
discriminatorio para la liberalización progresiva del comercio y para promover el comercio mundial, basado en las normas acordadas por sus miembros (APEC, 2018).

En términos generales, el contenido de este parágrafo era aceptable para los representantes estadounidenses, pero hemos resaltado en itálicas el pasaje que los incomodaba: normas establecidas por consenso y por encima de los intereses estadounidenses. Para ellos, como hemos señalado, el estado de derecho no es sino el derecho de los Estados Unidos a imponer sus intereses en los marcos bilaterales anunciados por Donald Trump. De allí que, en el parágrafo 8, las menciones al mejoramiento de las funciones de la OMC como supervisora de las relaciones entre sus miembros y el rechazo del proteccionismo unilateral hayan sido entendidas como expresiones de reprobación para la política económica internacional de la administración Trump:

8. Para mejorar el funcionamiento de la OMC y cumplir con todos sus miembros, nos comprometemos a trabajar juntos para mejorar sus funciones de negociación, monitoreo y solución de controversia. También alentamos a las economías de APEC a aumentar su participación en la OMC para avanzar en su trabajo. También apoyamos la reforma necesaria de la OMC, a fin de mejorarla y fortalecerla para enfrentar mejor los desafíos comerciales mundiales existentes y emergentes. Acordamos luchar contra el proteccionismo, incluidas todas las prácticas comerciales desleales (APEC, 2018).

Finalmente, en el parágrafo 9, los ministros volvían a poner énfasis sobre la función general de la OMC como supervisora de las prácticas comerciales de sus miembros y sobre la necesidad de apegarse a las normas de la organización; los representantes estadounidenses en la reunión ministerial se apegaron al espíritu del discurso de Donald Trump, en Da Nang, para rechazar ambas ideas y privilegiar la asimetría favorable para los Estados Unidos en todas las relaciones bilaterales posibles. Asimismo, y dado que la facilitación del comercio es un mecanismo de apertura comercial, el Acuerdo sobre Facilitación del Comercio, alcanzado en la OMC, también debió provocar escozor entre los representantes estadounidenses.

9. Reafirmamos la importancia del trabajo de supervisión del comercio realizado por la OMC y hacemos llamamientos a todos los miembros de la OMC para que mejoren la adhesión a las normas de la organización. Tomamos nota del progreso de las economías de APEC en la 
puesta en práctica del Acuerdo sobre Facilitación del Comercio (AFC), alcanzado en la OMC. Damos la bienvenida a otras actividades para la creación de capacidades en APEC, incluidas aquellas que apoyan la puesta en práctica de obligaciones relacionadas con la transparencia para apoyar la implementación del AFC por parte de las economías en cooperación con las partes interesadas relevantes (APEC, 2018).

En tanto que, tras bambalinas, se desarrollaba la querella estadounidense contra las medidas del resto de los miembros de APEC para fortalecer la OMC, el vicepresidente Pence no escatimaba comentarios para señalar directamente a China como la causante de la decadencia económica estadounidense; nótese que, mientras Donald Trump se refería de manera indirecta a las autoridades chinas recurriendo al pronombre "ellos", el vicepresidente los señalaba de manera directa:

Y aunque hemos estado forjando nuevos acuerdos, también nos hemos enfrentado a países que utilizan prácticas comerciales desleales. Tan sólo miren la posición asumida por el presidente Trump en nuestra relación comercial con China.

Como dijo el presidente Trump hace unas horas en la Oficina Oval, tenemos "un gran respeto por el presidente Xi... [y] un gran respeto por China". Pero en palabras del presidente "China se ha aprovechado de los Estados Unidos por muchos, muchos años". Y esos días han terminado.

Como ha añadido el presidente, China tiene "tremendas barreras", tiene "tarifas tremendas"; y, como todos sabemos, el país impone, en una escala sin precedentes, cuotas forzadas, transferencia de tecnología y de propiedad intelectual, así como subsidios industriales. Tales acciones han generado a los Estados Unidos un déficit en el comercio de bienes, por 375 mil millones de dólares, tan sólo el año pasado. Pero como dijo el presidente hoy "todo eso ha cambiado ahora".

Hemos tomado medidas decisivas para abordar nuestro desequilibrio comercial con China. Hemos impuesto tarifas sobre productos chinos, por un valor de 250 mil millones de dólares, y podríamos duplicar esa cantidad. Pero esperamos algo mejor. Sin embargo, los Estados Unidos no cambiarán de rumbo hasta que China cambie sus formas (Pence, 2018).

Con el sabotaje del proyecto de William Clinton sobre la Comunidad del Pacífico, Donald Trump ha cerrado dos círculos en la política exterior: el primero de ellos es el de la política de "contención sin aislamiento" de China. Como hemos visto, la administración de 
William Clinton dio el primer paso en esa dirección, con sus intentos tímidos de aislar política y económicamente a China; con la confrontación directa, Donald Trump ha hecho añicos tanto los mecanismos multilaterales, construidos laboriosamente desde finales de la Segunda Guerra Mundial, como los bilaterales, abocados a guiar la evolución internacional de China. Hasta ahora, la práctica ha demostrado que, por primera vez, el gobierno estadounidense se encuentra ante un contrincante carente de ataduras que lo subordinen a los Estados Unidos, dotado de recursos económicos prácticamente ilimitados y dispuesto a defender sus propios intereses. Con el rompimiento del statu quo, la administración Trump se aventura en tierras desconocidas.

El segundo círculo concluido está referido al desarrollo de APEC. Como los chinos en la década de 1990, la administración Trump no sólo ha cambiado la música para la liberalización comercial y financiera, sino que se ha llevado la fiesta a América del Norte; quienes se han sumado a ella, han debido pagar un derecho de entrada que rompe el proyecto de APEC sobre una Comunidad de Asia Pacífico, ya no digamos basada en el regionalismo abierto, sino en un ALCAP carente de contenido sin la participación estadounidense. Sin éste y con los nuevos acuerdos comerciales de los Estados Unidos (AMEC, EU-Corea y EUJapón), los integrantes de APEC no tienen nada para rendir cuentas, en 2020, cuando se cumpla la segunda fecha de las Metas de Bogor.

\section{CONCLUSIONES}

Para el observador del desarrollo de APEC, el futuro post-2020 parecería algo más que incierto; sin embargo, si algo ha redituado la política estadounidense de "contención sin aislamiento" de China es la utilidad de los mecanismos multi y bilaterales para limitar los efectos perturbadores de las acciones imprevistas de rogue States, es decir, de Estados o gobiernos situados fuera de los marcos institucionales internacionales. En 1990, Lee Kwan Yew así lo había entendido cuando propuso la inclusión de las tres Chinas en APEC. A partir de ahora y por más incómodo que resulte el tono antichino y antiliberalización económica de los representantes estadounidenses, "contener sin aislamiento" a los Estados Unidos habrá de ser uno de los objetivos centrales del foro. 
Con el fin del ciclo de APEC, marcado por el proyecto de la Comunidad del Pacífico basado en la liberalización económica — unilateral y voluntaria o regulada por ACR-, parecería que la reinvención del foro pasa por la recuperación del proyecto original de un mecanismo de diálogo y de consulta en materia de cooperación intergubernamental, cuyas decisiones sigan siendo no vinculantes $y$, cuando las circunstancias lo permitan, basadas en el consenso. No se trata simplemente de volver al pasado, sino, parafraseando a Bob Dylan, de superarlo mostrando que la madurez del foro implica su rejuvenecimiento. Esta renovación ya está inscrita en las instancias institucionales y en el funcionamiento de APEC: a lo largo del siglo XXI, el foro ha dejado de ser un mecanismo intergubernamental de cooperación económica y técnica, para devenir uno orientado a la cooperación política en un sentido muy amplio. Las circunstancias actuales exigen la supervivencia de un APEC que acentúe y extienda esa cooperación a nuevos ámbitos de las relaciones intergubernamentales.

La cooperación política intergubernamental será tanto más necesaria, cuanto más se precise el nuevo orden global delineado por el proyecto de Donald Trump de crear un complejo económico transregional, con América del Norte en el centro y con radios que conectan el epicentro tanto con Asia (Corea y Japón), como con Europa (Alemania, Italia, Irlanda y Reino Unido). El lector atento notará con preocupación que, con excepción de México, el proyecto estadounidense engloba las principales economías avanzadas; en ese sentido, podríamos decir que el nuevo orden global sería dual y constituido por el bloque transregional encabezado por los Estados Unidos y por el resto del mundo, donde China mantendría una posición predominante. En la lógica de la administración Trump, elementos del resto del mundo podrían integrarse al bloque transregional en la medida en que la pertenencia a éste muestre ofrecer mayores ventajas y que los dirigentes gubernamentales estén dispuestos a privilegiar la relación bilateral con los Estados Unidos. En ese marco, APEC, como foro de cooperación política intergubernamental, sería necesario más que nunca para limitar las fricciones entre los dos sectores de la economía dual, en el marco de la región del Pacífico.

Desde ahora, ya están fincadas las bases de este desarrollo probable; su consolidación depende, a la vez, de los tiempos y de la continuidad de la política estadounidenses. Los tiempos estadounidenses, sin duda, están marcados por una agenda política que oscila entre 
la destitución de Donald Trump y su reelección; la continuidad dependerá de la reelección o de la disposición de algún eventual sucesor del actual presidente de hacer suyo el proyecto sobre el nuevo orden global.

\section{REFERENCIAS}

Akamatsu, Kaname (1962). "A Historical Pattern of Economic Growth in Developing Countries”. Recuperado de https://onlinelibrary.wiley.com/doi/pdf/10.1111/j.17461049.1962.tb01020.x

APEC (1990). 1990 APEC Ministerial Meeting. Recuperado de http://apec.org/Meeting-Papers/ Annual-Ministerial-Meetings/1990/1990_amm

APEC (1991). 1991 APEC Ministerial Meeting. Recuperado de http://apec.org/Meeting-Papers/ Annual-Ministerial-Meetings/1991/1991_amm/annex_b_seoul_apec

APEC (1993). 1993 Leaders' Declaration. Recuperado de http://apec.org/Meeting-Papers/ Leaders-Declarations/1993/1993_aelm

APEC (1993b). A Vision for APEC: Towards an Asia Pacific Economic Community. Report of the Eminent Persons Group to APEC Ministers. Recuperado de https://www.apec.org/ Publications/1993/12/A-Vision-for-APEC-Towards-an-Asia-Pacific-Economic$\underline{\text { Community-1993 }}$

APEC (1995). Selected APEC Documents 1989-1994, APEC Secretariat, febrero.

APEC (2003). 2003 Leaders' Declaration. Recuperado de http://apec.org/Meeting-Papers/ Leaders-Declarations/2003/2003 aelm

APEC (2004). 2004 Leaders' Declaration. Recuperado de http://apec.org/Meeting-Papers/ Leaders-Declarations/2004/2004_aelm

APEC (2005). 2005 Leaders' Declaration. Recuperado de http://apec.org/Meeting-Papers/ Leaders-Declarations/2005/2005_aelm

APEC (2010). 2010 Leaders' Declaration. Recuperado de http://apec.org/Meeting-Papers/ Leaders-Declarations/2010/2010_aelm 
APEC (2011). Recuperado de http://apec.org/Meeting-Papers/Leaders-Declarations/2011/ 2011 aelm

APEC (2015). Annex A. The Beijing Roadmap for APEC's Contribution to the Realization of the FTAAP. Recuperado de http://apec.org/Meeting-Papers/Leaders-Declarations/ 2014/2014_aelm/2014_aelm_annexa

APEC (2017). 2017 Leaders' Declaration. Recuperado de http://apec.org/Meeting-Papers/ Leaders-Declarations/2017/2017_aelm

APEC (2018). 2018 APEC Ministerial Meeting. Recuperado de http://apec.org/MeetingPapers/Annual-Ministerial-Meetings/2018/2018 amm

APEC (2018b). 2018 Chair's Statement. Recuperado de http://apec.org/Meeting-Papers/ Leaders-Declarations/2018/2018 aelm

China Briefing (2019). The US-China Trade War: A Timeline. Recuperado de https:// www.china-briefing.com/news/the-us-china-trade-war-a-timeline/

Clinton, Hillary (2011). “America’s Pacific Century”. Recuperado de https://foreignpolicy. $\underline{\text { com/2011/10/11/americas-pacific-century/ }}$

Das, Sanchita B. (2013). The Trans-Pacific Partnership as a tool to contain China: myth or reality? Recuperado de https://www.eastasiaforum.org/2013/06/08/the-trans-pacificpartnership-as-a-tool-to-contain-china-myth-or-reality/

Garnault, R., y Song, L. (2006). China, New Engine of World Growth. Recuperado de https://press-files.anu.edu.au/downloads/press/p214371/pdf/book.pdf

Kissinger, Henry (2011). On China. Recuperado de https://polscibooks.files.wordpress. com/2016/01/kissinger-2011-on-china.pdf

Nixon, Richard M. (1967). “Asia after Viet Nam”. Recuperado de http://www.jstor.org/ $\underline{\text { stable/20039285 }}$

Pence, Mike (2018). "Remarks by Vice President Pence at the 2018 APEC CEO Summit. Port Moresby, Papua New Guinea". Recuperado de https:/www.whitehouse.gov/ 
briefings-statements/remarks-vice-president-pence-2018-apec-ceo-summit-portmoresby-papua-new-guinea/

Ramírez Bonilla, Juan J. (2006). "La República Popular China y el sudeste asiático: del distanciamiento a la asociación económica”. En Estrada, José L., et al., China en el siglo XXI. Economía, política y sociedad de una potencia emergente, México, Universidad Autónoma Metropolitana-Iztapalapa.

Ramírez Bonilla, Juan J. (2019). "La administración Trump y la transición del proteccionismo consensuado al proteccionismo coercitivo". En León Manríquez, José L., Asia Pacifico: poder y prosperidad en la era de desglobalización, en prensa, México, Universidad Autónoma Metropolitana-Xochimilco.

The White House, President Barack Obama, s.f. "The Trans-Pacific Partnership. What You Need to Know about President Obama's Trade Agreement". Recuperado de https://obamawhitehouse.archives.gov/issues/economy/trade

Trump, Donald (2016). "Full transcript: Donald Trump's jobs plan speech". Recuperado de https://www.politico.com/story/2016/06/full-transcript-trump-job-plan-speech$\underline{224891}$

Trump, Donald (2017). "Remarks by President Trump at APEC CEO Summit. Da Nang, Vietnam". Recuperado de https://www.whitehouse.gov/briefings-statements/remarks -president-trump-apec-ceo-summit-da-nang-vietnam/

United Nations Statistics Division, s.f. "National Accounts, GDP and its breakdown at constant 2010 prices in US dollars". Recuperado de https://unstats.un.org/ unsd/snaama/downloads

Wikipedia, s.f.a., "Regional Comprehensive Economic Partnership". Recuperado de https://en.wikipedia.org/wiki/Regional_Comprehensive_Economic_Partnership

Wikipedia, s.f.b., “APEC Papua New Guinee 2018”. Recuperado de https://en.m. wikipedia.org/wiki/APEC_Papua_New_Guinea_2018

World Trade Organization, s.f., "Regional Trade Agreements Data Base". Recuperado de http://rtais.wto.org/UI/PublicAllRTAListAccession.aspx 
Zhang, Kevin H. (2006). China as the World Factory. Recuperado de https://www.book2 look.com/embed/9781135992897 